\author{
Д.М. Савинов , Е. С. Скачедубова ${ }^{2}$, А.Е. Сомова \\ Институт русского языка им. В. В. Виноградова РАН \\ (Россия, Москва) \\ crillon@yandex.ru', skaekaterina@yandex.ru', alsomova@yandex.ru ${ }^{3}$
}

\title{
ИЗ ОПЫТА РАБОТЫ НАД ШКОЛЬНЫМ СЛОВАРЕМ УДАРЕНИЙ: АКЦЕНТУ АЦИЯ ФОРМ ПРОШЕДШЕГО ВРЕМЕНИ НЕВОЗВРАТНЫХ ГЛАГОЛОВ
}

Статья посвящена анализу соотношения нормы и узуса в акцентуации невозвратных глаголов непродуктивных классов в форме прошедшего времени. В данной работе на основе данных, полученных в результате серии экспериментов, которые отражают актуальное произношение носителей современного русского литературного языка, делается вывод о необходимости корректировки кодификационных решений современных орфоэпических словарей.

Ключевые слова: глагол, акцентуация, орфоэпия, норма, кодификация

0. Одна из задач орфоэпического словаря - сообщать сведения об ударении. В словари включаются слова и словоформы, при произнесении которых могут возникать затруднения в постановке ударения. Эти затруднения вызваны особенностями русского ударения, которое, как известно, свободно (может падать на любой слог) и подвижно, т. е. при изменении слова может в разных формах перемещаться с одной морфемы на другую. Считается, что нормы постановки ударения в современном русском литературном языке описаны достаточно полно и кодифицированы в различных словарях и справочниках.

Однако звуковой строй русского языка непрерывно развивается, что приводит к естественному изменению некоторых сложившихся закономерностей в области ударения. Если «старшая» норма достаточно подробно изучена и описана (например в работах Н.А. Еськовой, В. Л. Воронцовой, Р.Ф. Касаткиной), то системных описаний «младшей» акцентологической нормы, основанных на социолингвистических экспериментах, очень мало. Недостаток таких описаний отражается на качестве орфоэпических словарей, в которых можно наблюдать, во-первых, разнобой в акцентологических рекомендациях, а во-вторых, расхождение рекомендаций и узуса. Орфоэпические словари не всегда объективно отражают тенденции быстро развивающегося живого разговорного языка, а потому многие формы, 
существующие в речи его носителей, считаются нелитературными. Перед составителем словаря стоит очень сложная задача: определить, где находится грань между вариантом, который уже необходимо квалифицировать как допустимый в литературном языке, и вариантом, который еще или уже следует признавать неправильным.

В данной статье будет рассмотрена акцентуационная вариативность в формах прошедшего времени невозвратных глаголов. Как известно, в русском языке большинство глаголов при словоизменении сохраняют ударение исходной словоформы, т.е. имеют неподвижное ударение как в основе настоящего (будущего простого) времени, так и в основе инфинитива. Подвижное ударение в прошедшем времени свойственно лишь небольшой группе глаголов, относящихся к непродуктивным классам. Эти же глаголы обычно характеризуются и высокой степенью вариативности ударения в соответствующих формах.

Чтобы определить основные закономерности постановки ударения в исследуемых глаголах, была проведена серия экспериментов: респондентам различного пола, трех возрастных групп (младшая — до 29 лет включительно, средняя - от 30 до 59 лет, старшая - 60 лет и старше), москвичам во втором-третьем поколении, носителям литературной нормы русского языка, были предложены для чтения тексты, содержащие глагольные формы, допускающие в разговорной речи варианты ударения. В эксперимент входили следующие невозвратные глаголы и их префиксальные производные: взять, лить, вить, гнать, дать, врать, драть, брать, жить, пить, пльтьь, рвать, спать, ткать, быть, слать, стлать, жрать, ждать, лгать, клясть, звать, красть, а также префиксальные образования с корнями был-, ня- и мер- (типа убыть, принять, умереть).

\section{1. Формы среднего рода}

Подавляющее большинство исследованных глаголов в раннедревнерусском языке были энклиноменами, соответственно, ударение во всех формах прошедшего времени кроме формы ж. р. ед. ч. исконно должно было падать либо на корень / суффикс (у непроизводных бесприставочных глаголов), либо на приставку (у префиксальных производных). По данным Л.А. Булаховского и Н. А. Еськовой, этот принцип в целом сохранялся до конца XVIII — начала XIX в.: да́ло, о́бвил, при́брало, по́пльлло, со́рвали и др. [Булаховский 1948: 215-219, 224-225; Еськова 2008: 375-389]. Однако уже с первой половины XIX в. прослеживается тенденция «к “выравниванию” ударения приставочных глаголов по осно́вному» [Воронцова 2000: 308], т. е. к перемещению ударения на основу — по аналогии с производящими бесприставочными глаголами в соответствующих формах.

Проведенный нами анализ текстов XVIII-XIX вв. поэтического подкорпуса Национального корпуса русского языка (далее НКРЯ) дал возможность обнаружить немалое количество примеров приставочных и бесприставочных глаголов, в которых ударение в ср. р. падает не только на приставку, корень или суффикс, но и на окончание. Следует отметить, что наиболее часто нафлективное ударение 
встречается, по данным материалов НКРЯ, в бесприставочных глаголах. Приведем лишь некоторые примеры: «Меж бледных звезд Как человеческое было Лицуо луныл, и слезы ли́ло» (А.Н. Майков, 1853) — «Оно, горевшее светло, Как бы зияющзая рана Болезни смрадные лило́» (А. М. Жемчужников, 1867); «По плечам твоим высоким Солнце блеск разли́ло свой. И знакомые мне косы Льнут к волнам своей волной» (К.К. Случевский, 1897) - «И чудное, исполненное ласки Создание - на щзеки, на чело Как будто воск холодный разлило́, И я застыл в окаменелой маске» (К.М. Фофанов, 1892); «Весь свет непрестанно Терпит отмень, и то чудно лишь бы было, Если б мое в тех валах судно равно пльі́ло» (А. Д. Кантемир, 1731-1743) - «Пльло́ бы все ко мне: из темныя конурки Морской бы вышел рак, кобенясь на клешнях; Явился бы и кит с огромными усами, И нильский крокодил в узорных чешуях» (В.А. Жуковский, 1819); «Светила чудные сияли в вылине И, ульгбаяся, смотрели в душу мне; Чистейшим серебром поля вдали сияли, Леса пустынные недвижимо стояли; Все спа́ло...» (А.Н. Апухтин, 1854) - «Сидела мать у кольбели; Дитя спало́, но в странном сне...» (Н. П. Огарев, 1841); «Что зва́ло жить, что силь горячило - Далеко за горой» (А. А. Фет, 1853) - «Надменное ветрило Его звало́ к брегам чужой земли...» (А.С. Пушкин, 1814); «Я пел одинок, но тужить и роптать Мне, старому, было б грешно и нестать - Наград мое сердие не жәда́ло!» (А. К. Толстой, Слепой, 1873) - «Это все, поверь, Нас жждало́ давно, И сбылось теперь, чему быть должно» (А .Н. Апухтин, 1854-1892) и др.

Современные орфоэпические словари формы ср. р. с ударением на окончании (типа лило́, разлило́, гнало́, загналó, бралó, набрало́, ждалó и др.) дают с запретительной пометой не рекомендовано, допустимыми признаются формы взяло́ и дало́ [Еськова 2014; Аванесов (ред.) 1999; Резниченко 2008] или только дало́ [Штудинер 2016]. Лишь в Большом орфоэпическом словаре варианты с нафлективным ударением в форме ср. р. трактуются как нормативные и снабжены пометой допустимо младшее [Каленчук и др. 2017].

Результаты проведенного эксперимента показали, что носители современного русского литературного языка произносят данные формы преимущественно с ударением на окончании, причем часто процент таких произнесений имеет тенденцию к возрастанию от старшей к младшей возрастной группе. Обращает внимание, что в непроизводных бесприставочных глаголах процент произнесения с ударным окончанием значительно выше, чем в производных, для ряда лексем он приближается или равен $100 \%$. Наиболее часто формы ср. р. с нафлективным ударением встречаются в глаголах лить, дать, звать, взять и их префиксальных производных: ли́ло (10\% ст. и мл., $0 \%$ ср.) и лило́ (90\% ст. и мл., $100 \%$ ср.); за́лило (30\% ст., $20 \%$ ср., $0 \%$ мл.), зали́ло (20\% ст., $0 \%$ ср., $10 \%$ мл.) и залило́ (50\% ст., $80 \%$ ср., $90 \%$ мл.); разли́ло (30\% ст., $10 \%$ ср., $0 \%$ мл.) и разлило́ (70\% ст., $90 \%$ ср., $100 \%$ мл.); да́ло (0\% ст. и мл., $10 \%$ ср.) и дало́ (100\% ст. и мл., $90 \%$ ср.); по́дало (40\% ст., $30 \%$ ср., $30 \%$ мл.), пода́ло (10\% ст. и мл., $30 \%$ ср.) и подало́ (50\% ст., $40 \%$ ср., $60 \%$ мл.); пере́дало (17\% ст., $20 \%$ ср., $10 \%$ мл.), переда́ло (8\% ст., $20 \%$ ср., $0 \%$ мл.) и передало́ (75\% ст., $60 \%$ ср., $90 \%$ мл.); зва́ло (10\% ст. и мл., 0\% ср.) и звало́ (90\% ст. и мл., $100 \%$ ср.); подозва́ло (80\% ст., $50 \%$ ср., $20 \%$ мл.) и подозвало́ (20\% 
ст., $50 \%$ ср., $80 \%$ мл.); призва́ло (50\% ст., $60 \%$ ср., $20 \%$ мл.) и призвало́ (50\% ст., $40 \%$ ср., $80 \%$ мл.) и др.

Глаголы брать, гнать и жить в целом вписываются в общий процесс переноса ударения на окончание, о чем свидетельствуют некоторые словоформы: бра́ло (40\% ст., $20 \%$ ср. и мл.) и брало́ (60\% ст., $80 \%$ ср. и мл.); набра́ло (50\% ст., 30\% ср., $10 \%$ мл.) и набрало́ (50\% ст., $70 \%$ ср., $90 \%$ мл.); отобра́ло (17\% ст., $40 \%$ ср., $10 \%$ мл.) и отобрало́ (83\% ст., $60 \%$ ср., $90 \%$ мл.); прибра́ло (30\% ст., 20\% ср. и мл.) и прибрало́ (70\% ст., $80 \%$ ср. и мл.); гна́ло (30\% ст., $40 \%$ ср., $10 \%$ мл.) и гналó (70\% ст., $60 \%$ ср., $90 \%$ мл.); загна́ло (30\% ст., $50 \%$ ср., $20 \%$ мл.) и загнало́ (70\% ст., $50 \%$ ср., $80 \%$ мл.); обогна́ло (40\% ст., $60 \%$ ср., $40 \%$ мл.) и обогнало́ (60\% ст., $40 \%$ ср., $60 \%$ мл.); жи́ло (30\% ст., $60 \%$ ср., $10 \%$ мл.) и жило́ (70\% ст., $40 \%$ ср., $90 \%$ мл.); о́бжило (0\% ст. и мл, $10 \%$ ср.), обжи́ло (30\% ст. и мл., $40 \%$ ср.) и обжило́ (70\% ст. мл, $50 \%$ ср.); за́жило (60\% ст., $30 \%$ ср., $20 \%$ мл.), зажи́ло (0\% ст. и мл, $10 \%$ ср.) и зажило́ (40\% ст., $60 \%$ ср., $80 \%$ мл.), о́жило (40\% ст., 20\% ср., $50 \%$ мл.), ожи́ло (10\% ст., $0 \%$ ср. и мл.) и ожило́ (50\% ст. и мл., $80 \%$ ср.).

Однако достаточно большое количество приставочных образований от этих глаголов до сих пор последовательно сохраняет наосновное окончание: избра́ло (60\% ст., 100\% ср., $70 \%$ мл.) и избрало́ (40\% ст., 0\% ср., 30\% мл.); разобра́ло (60\% ст., $50 \%$ ср., $70 \%$ мл.) и разобрало́ (40\% ст., 50\% ср., 30\% мл.); перебра́ло (80\% ст., $40 \%$ ср., 70\% мл.) и перебрало́ (20\% ст., 60\% ср., 30\% мл.); обобра́ло (40\% ст., $70 \%$ ср. и мл.) и обобрало́ (60\% ст., 30\% ср. и мл.); изгна́ло (42\% ст., $80 \%$ ср., $50 \%$ мл.) и изгналó (58\% ст., $20 \%$ ср., $50 \%$ мл.); пригна́ло (90\% ст., $100 \%$ ср., $30 \%$ мл.) и пригнало́ (10\% ст., 0\% ср., $70 \%$ мл.); догна́ло (80\% ст., 60\% ср., $50 \%$ мл.) и догнало́ (20\% ст., $40 \%$ ср., $50 \%$ мл.); нагна́ло (70\% ст., $80 \%$ ср., $80 \%$ мл.) и нагнало́ (30\% ст., 20\% ср., $20 \%$ мл.); о́тжило (20\% ст. и мл., $100 \%$ ср.), отжи́ло (60\% ст. и мл., $100 \%$ ср.) и отжило́ (20\% ст. и мл., $30 \%$ ср.); до́жило (70\% ст., 40\% ср., 20\% мл.), дожи́ло (20\% ст. и ср., $50 \%$ мл.) и дожило́ (10\% ст., $40 \%$ ср., $30 \%$ мл.); по́жило (20\% ст. и ср., $0 \%$ мл.), пожи́ло (60\% ст. и мл., $50 \%$ ср.) и пожило́ (20\% ст., 30\% ср., $40 \%$ мл.); пе́режило (10\% ст., $20 \%$ ср. и мл.), пережи́ло (70\% ст., 30\% ср., 60\% мл.) и пережило́ (20\% ст. и ср., $50 \%$ мл.).

Есть и другие исключения. Во-первых, особняком стоят глаголы вить и пuть, относящиеся к одному классу. Так, в глаголе вить и префиксальных производных в ср. р. ударение чаще падает на основу: ви́ло (80\% ст. и ср., $100 \%$ мл.) и вило́ (20\% ст. и ср., $0 \%$ мл.), уви́ло (75\% ст., $90 \%$ ср., $100 \%$ мл.) и увило́ (25\% ст., $10 \%$ ср., $0 \%$ мл.), приви́ло (60\% ст., $90 \%$ ср., 80\% мл.) и привило́ (40\% ст., $10 \%$ ср., 20\% мл.), сви́ло (60\% ст., $80 \%$ ср. и мл.) и свило́ (40\% ст., $20 \%$ ср. и мл.), зави́ло (70\% ст. и мл., $80 \%$ ср.) и завило́ (30\% ст. и мл., $20 \%$ ср.).

Глаголы с корнем $n u$ - имеют нафлективное ударение несколько чаще, чем глаголы с корнем ви-, однако количество респондентов, поставивших ударение на окончание, не превышает 30-40\%: пи́ло (90\% ст., 80\% ср., 70\% мл.) и пило́ (10\% ст., 20\% ср., $30 \%$ мл.), отпи́ло (80\% ст., $40 \%$ ср., $70 \%$ мл.) и отпило́ (20\% ст., $60 \%$ ср., 30\% мл.), допи́ло (80\% ст. и ср., $70 \%$ мл.) и допило́ (20\% ст. и ср., $30 \%$ мл.), попи́ло (60\% у всех групп респондентов) и попило́ (40\% у всех групп респондентов). 
Следует отметить, что в отличие от всех остальных глаголов с исконно подвижной акцентной парадигмой, у вить и пить максимальное количество произнесений с ударением на флексию фиксируется не в производящих бесприставочных глаголах, а в префиксальных производных: количество произнесений привило́, свило́, завило́, попило́, отпило́ значительно превышает количество произнесений вило́ и пило́. Возможно, стабильное сохранение ударения на основе в ср. р. связано с влиянием других глаголов данного класса, большинству которых в прошедшем времени свойственно неподвижное ударение на основе: бuть, uить, брить, крыть, мыть и др. Кроме того, в случае с глаголом вить и его префиксальными производными такая акцентуация объясняется разграничением омонимии с формами глагола вести́ и соответствующими производными: ви́ло, но вело́, приви́ло, но привело́ и др.

Во-вторых, у глаголов слать, стлать, красть, ткать с исконно неподвижным наосновным ударением в формах прошедшего времени процент произнесений форм ср. р. с ударением на окончании не превышает 10-20\%, причем обычно в младшей или, реже, в средней группе респондентов. Респонденты старшей возрастной группы произносят эти формы преимущественно с ударением на основе: сла́ло, засла́ло, посла́ло, пересла́ло, досла́ло, стла́ло, устла́ло, разостла́ло, постла́ло, кра́ло, укра́ло; тка́ло, натка́ло и др.

Наконец, небольшое количество префиксальных глаголов произносится преимущественно с ударением на приставке: предпри́няло: $100 \%$ ст., $90 \%$ ср. и $90 \%$ мл., по́няло: $90 \%$ ст., $70 \%$ ср., $60 \%$ мл., на́няло: $80 \%$ ст. и $80 \%$ ср., $60 \%$ мл.; при́няло: $100 \%$ ст., $80 \%$ ср. и $80 \%$ мл., при́было: $100 \%$ ст. и $100 \%$ ср., $90 \%$ мл., за́перло: $75 \%$ ст., 90\% ср., $90 \%$ мл.; о́тбыло: $30 \%$ ст., 60\% ср., 40\% мл.; у́было: $90 \%$ ст. и $90 \%$ ср., $80 \%$ мл., про́было (70\% ст. и мл., $80 \%$ ср.), про́кляло (70\% ст., 50\% ср., $60 \%$ мл.), за́мерло (100\% ст., $80 \%$ ср., $60 \%$ мл.), у́мерло (100\% ст. и ср., 90\% мл.). По всей видимости, здесь произошла лексикализация места ударения, которая, возможно, обусловлена постепенным «затемнением» словообразовательной мотивированности данных слов, их отрывом от производящей основы (npuбыmb, omбыmb, yбыть), а также наличием в глаголах связанного корня (понять, нанять, принять, запереть). К последней группе примыкают глаголы замереть и умереть, соотносимые с малоупотребительным разговорным глаголом мереть, который в современном русском языке имеет дефектную парадигму и употребляется исключительно в устойчивых сочетаниях (мрут как мухи). В случае с глаголом предпринять также действует тенденция к ритмическому равновесию.

\section{2. Формы женского рода}

У глаголов, исконно имевших в прошедшем времени подвижную парадигму, ударным в ж. р. ед. ч. было окончание. По данным НКРЯ, нафлективное ударение в этой форме стабильно сохранялось вплоть до XVIII-XIX вв. Примеры с ударением на основу начинают встречаться с первой половины XIX в., однако они немногочисленны: «Когда небесные все силь Призва́ла, дни свои кляня, И застонала: 
“Мильй, мильий, Ужель разлюбишь ты меня!”» (В.И. Туманский, 1833); «Совершенно умирала; Силь все свои собра́ла, Взлезла лишь - и все прошло, Сердце будто расивело» (И. П. Мятлев, 1840). Их количество несколько увеличивается только к началу XX в.

В современных орфоэпических словарях для глагольных форм женского рода прошедшего времени в качестве нормативного дается только вариант с нафлективным ударением (жила́, изжила́, рвала́, нарвала́ и др.). Результаты эксперимента показывают, что в этих формах в большинстве случаев ударение на окончании последовательно сохраняется. Более того, нафлективное ударение в формах ж. p. становится возможным и для глаголов, ранее имевших в прошедшем времени неподвижное ударение на основе: слать, стлать, красть. Так, вариант слала́ предпочли $20 \%$ ст., $20 \%$ ср., $40 \%$ мл., послала́: 30\% ср. и $30 \%$ мл., отослала́: $10 \%$ ср., $50 \%$ мл.; стлала́: $10 \%$ ст., $50 \%$ ср., $40 \%$ мл.; постлала́: $10 \%$ ст., $30 \%$ ср., $10 \%$ мл.; крала́: $60 \%$ ст., $50 \%$ ср., $70 \%$ мл. Очевидно, что количество произнесений с ударением на окончании в этих глаголах постепенно увеличивается.

Варианты слала́ и стлала́ спорадически фиксируются в поэзии начиная с конца XIX в.: «И не подумаешь, что злобно Здесь ночью снежная метель С своею песнею надгробной Стлала́ холодную постель» (К. М. Фофанов, 1887); «Еще Аравия тирана Сюда такого не слала́, Еще над селами Ирана Тень не была такого зла» (Г. В. Адамович, 1918-1920). В словаре под редакцией Д. Н. Ушакова формы стла́ла и стлала́ признаются равноправными, а вариант слала́ снабжается пометой «областное» [Ушаков 1940:. 256, 522]. В других орфоэпических источниках нормативным в этих формах считается только вариант с наосновным ударением.

Акцентные варианты крала́, украла́ в НКРЯ не зафиксированы, во всех источниках (включая словарь под редакцией Ушакова) единственно правильными признаются варианты с ударением на корне: кра́ла, укра́ла. Лишь в Большом орфоэпическом словаре вариант крала́ признается нормативным и дается с пометой допустимо младшее [Каленчук и др. 2017: 326].

Особо следует остановиться на префиксальных производных от глаголов гнать и ткать, которые, по данным эксперимента, довольно часто произносятся в ж. р. с ударением на суффиксе: изгна́ла (30\% ст., $40 \%$ cp., $10 \%$ мл.), погна́ла (70\% ст., $10 \%$ ср., $30 \%$ мл.), вогна́ла (30\% ст., $20 \%$ ср., 10\% мл.), пригна́ла (30\% ст., 20\% ср., $10 \%$ мл.), догна́ла (30\% ст., $10 \%$ ср. и мл.), угна́ла (50\% ст., $40 \%$ ср., $10 \%$ мл.), обогна́ла (10\% ст., $30 \%$ ср., $0 \%$ мл.), перегна́ла (10\% ст., 30\% ср., $0 \%$ мл.), нагна́ла (30\% ст., $20 \%$ ср., $10 \%$ мл.), тка́ла (30\% ст. и ср., $10 \%$ мл.), натка́ла (20\% ст. и ср., $30 \%$ мл.). Исконно все формы, образованные от основы инфинитива этих глаголов, имели акцентную парадигму $a$, т. е. постоянное ударение на глагольном суффиксе, см. [Зализняк 1985: 125-139]. Позднее в результате влияние аналогии со стороны других глаголов с основой на $-a$, имевших подвижную парадигму (брать, врать, драть и др.), у гнать и ткать в формах прошедшего времени колонное ударение на основе сменилось подвижным: в ж. р. оно перешло на флексию, а в остальных формах закрепилось на суффиксе. При этом следы старой парадигмы $a$ сохранялись еще долгое время. Так, в поэзии XVIII в. широко 
представлены формы с наосновным ударением в ед. ч. ж. р. соответствующих глаголов: «Нагна́ла бабушка пред свадьбой внучке скуку, Рассказывая ей про свадебну науку» (А. П. Сумароков, 1759), «Иль сами естество оставили в саду, Или Натура их изгна́ла за вражду» (Ф.Я. Козельский, 1769); «Погна́ла все зима, - один тьь всех упряме» (М.Н. Муравьев, 1776); «И там бы для утех открылся новый трон; На нем бы Дашинька запела, заплясала, Лучом веселости прогна́ла б вечну ночь» (Н. А. Львов, 1796); «Не был наследником Аттала, Не обитаю я двориуов И тканей в дар, что Спарта тка́ла, Не получаю от льстециов» (В. В. Попугаев, 1799).

Словарь под редакцией Д. Н. Ушакова квалифицирует формы тка́ла и ткала́ как равноправные варианты (но только наткала́, соткала́ и др.) [Ушаков (ред.) 19351940]. В более поздних орфоэпических источниках равноправными вариантами признаются также натка́ла и наткала́, сотка́ла и соткала́ и др. [Аванесов (ред.) 1999; Резниченко 2008]. Большой орфоэпический словарь как основные дает формы с ударением на окончании: ткала́, наткала́, соткала́ и др., формы с ударением на суффиксе снабжаются пометой допустимо [Каленчук и др. 2017]; М. А. Штудинер считает единственно правильными варианты с ударением на окончании: ткала́ и др. [Штудинер 2016].

Наосновное ударение в ж. р. фиксируется и у глаголов, исконно имевших в прошедшем времени подвижную парадигму. Наиболее часто такая акцентуация отмечается в некоторых префиксальных производных от глаголов вить, numb, драть, брать, рвать и жрать. Приведем самые частотные формы, в которых процент подобной акцентуации равняется или превышает в отдельных возрастных группах 40\%: ви́ла (60\% ст., $50 \%$ ср. и мл.), уви́ла (30\% ст., $60 \%$ ср. и мл.), приви́ла (20\% ст., $50 \%$ ср. и мл.), нави́ла (30\% ст., $40 \%$ ср., $70 \%$ ст.), зави́ла (40\% ст., 30\% ср. и мл.), сви́ла (40\% ст., $0 \%$ ср., $30 \%$ мл.), пропи́ла (8\% ст., 0\% ср., $40 \%$ ст.), испи́ла (40\% ст. и ср., $20 \%$ мл.), распи́ла (40\% ст., 30\% ср., 0\% мл.), ободра́ла (20\% ст., $40 \%$ ср. и мл.), разодра́ла (40\% ст., $10 \%$ ср. и мл.), удра́ла (50\% ст., 20\% ср., 10\% мл.), подра́ла (40\% ст., 30\% ср. и мл.), обобра́ла (20\% ст., 40\% ср., 10\% мл.), изорва́ла (20\% ст., 50\% ср., $0 \%$ мл.), прорва́ла (40\% ст., $20 \%$ ср., 0\% мл.), пожра́ла (60\% ст., $0 \%$ ср., $20 \%$ мл.), сожра́ла (40\% ст., $0 \%$ ср. и мл.).

В остальных глагольных корнях ударение на основе в ж. р. характеризует обычно только отдельные слова с двусложной приставкой: недоли́ла, препода́ла, перевра́ла, перепль́лла, оболга́ла, что можно считать проявлением тенденции к ритмическому равновесию.

Можно предположить, что перенос ударения на основу в ж. р. глаголов с подвижной акцентной парадигмой у некоторых информантов объясняется региональным влиянием, поскольку в Западной диалектной зоне русского языка, а также в других восточнославянских языках части исследуемых глаголов свойственно неподвижное ударение на основе (бра́ла, дра́ла, зва́ла и др.).

О региональном распределении форм типа бра́ла, спа́ла - брала́, сnала́ в русских говорах см. [Касаткин (ред.) 2013: 165-166]. Акцентуация бра́ла, спа́ла обычно характеризует не только диалектный узус, но и речь местной интеллигенции, таким образом, накоренное ударение в форме ж. р. можно считать чертой, присущей 
западному региональному варианту русского литературного языка [Букринская, Кармакова 2012: 160].

3. Таким образом, для большинства невозвратных глаголов, исследованных в эксперименте, характерно формирование нового акцентного противопоставления единственного и множественного чисел: в ж. и ср. р. ед. ч. ударение падает на флексию, во мн. ч. - на основу. В частности, наличие этой тенденции подтверждает полное отсутствие в формах мн. ч. исследованных глаголов смещения ударения на окончание - его нет не только в разговорном узусе носителей русского литературного языка, но и в московском просторечии, тогда как формы с ударным окончанием в ср. р. ед. ч. постепенно становятся основными акцентными вариантами.

В заключение хочется отметить, что придание нормативного статуса тому или иному из существующих произносительных вариантов должно опираться не только на орфоэпические традиции кодификации, но и отражать основные тенденции развития русского литературного языка, прямо влияющие на разговорный узус. Можно констатировать, что нормы ударения, которые кодифицированы в современных словарях, требуют пересмотра и уточнения.

\section{Литература}

Аванесов Р.И. (ред.). Орфоэпический словарь русского языка: произношение, ударение, грамматические формы. 6-е изд. М., 1999. 687 с.

Букринская И. А., Кармакова О. Е. Языковая ситуация в малых городах России // Исследования по славянской диалектологии. Вып. 15: Особенности сосуществования диалектной и литературной форм языка в славяноязычной среде / Отв. ред. Л.Э. Калнынь. М., 2012. С. 153-164.

Булаховский Л.А. Русский литературный язык первой половины XIX века. Фонетика. Морфология. Ударение. Синтаксис. Киев, 1948. 466 с.

Воронцова В.Л. Активные процессы в области ударения // Русский язык конца ХХ столетия (1985-1995) / Отв. ред. Е. А. Земская. 2-е изд. М., 2000. С. 305-325.

Еськова Н.А. Нормы русского литературного языка XVIII-XIX веков: Ударение. Грамматические формы. Варианты слов. Словарь. Пояснительные статьи. М., 2008. 578 c.

Еськова Н.А. Словарь трудностей русского языка. Грамматические формы. М., 2014. $535 \mathrm{c}$.

Зализняк A.A. От праславянской акцентуации к русской. М., 1985. 429 с.

Каленчук М.Л., Касаткин Л.Л., Касаткина Р. Ф. Большой орфоэпический словарь русского языка. Литературное произношение и ударение начала XXI века: норма и ее варианты / Под ред. Л. Л. Касаткина. 2-е изд., исправ. и доп. М., 2017. 1022 с.

Касаткин Л.Л. (ред.). Русская диалектология. 3-е изд., исправ. и доп. М., 2013. 302 c.

Касаткина Р.Ф. Изменения в просодической системе русского литературного языка // Современный русский язык: Активные процессы на рубеже XX-XXI веков / Отв. ред. Л. П. Крысин. М., 2008. С. 375-398. 
Национальный корпус русского языка [Электронный ресурс]: база данных. Электрон. дан. Режим доступа: http://ruscorpora.ru (свободный). Загл. с экрана.

Резниченко И. Л. Словарь ударений русского языка. М., 2008. 944 с.

Ушаков Д. Н. (ред.). Толковый словарь русского языка: В 4 т. Т. 1. М., 1935; Т. 2. М., 1938; Т. 3. М., 1939; Т. 4, М., 1940.

Штудинер М.А. Словарь трудностей русского языка для работников СМИ. Ударение, произношение, грамматические формы. М., 2016. 590 с.

\section{Dmitry M. Savinov ${ }^{1}$, Ekaterina S. Skachedubova ${ }^{2}$, Alexandra E. Somova ${ }^{3}$}

Vinogradov Russian Language Institute of the Russian Academy of Sciences (Russia, Moscow)

crillon@yandex.ru ${ }^{1}$,skaekaterina@yandex.ru²,alsomova@yandex.ru ${ }^{3}$

\section{EXPERIENCE OF OVER ORPHOEPIC DICTIONARY: ACCENTUATION OF NONREFLEXIVE VERBS OF THE PAST TENSE FORMS}

The article is devoted to the accentuation of non-reflexive verbs in the form of the past tense. In this paper, on the basis of comparison of stress variants, codified by modern orthoepic dictionaries, and the data obtained as a result of experiments that reflect the actual pronunciation of modern Russian literary language speakers, the causes of changes occurring in the accent paradigm of non-reflexive verbs of the past tense are analyzed, the problems of codification of norms in the orthoepic dictionaries are raised.

Key words: verb, orthoepic dictionary, modern Russian literary language, accent, codification

\section{References}

Avanesov R.I. (ed.). Orfoepicheskii slovar' russkogo yazyka: proiznoshenie, udarenie, grammaticheskie formy [Pronouncing dictionary of the Russian language: pronunciation, accent, grammatical forms]. $6^{\text {th }} \mathrm{ed}$. Moscow, $1999.678 \mathrm{p}$.

Bukrinskaya I.A., Karmakova O.E. [Language situation in small towns of Russia]. Issledovaniya po slavyanskoi dialektologii. Vyp. 15: Osobennosti sosushchestvovaniya dialektnoi i literaturnoi form yazyka v slavyanoyazychnoi srede [Research on Slavic dialectology. Vol. 15: features of coexistence of dialect and literary forms of language in the Slavic-speaking environment]. L. E. Kalnyn' (ed.). Moscow, 2012. P. 153-164. (In Russ.)

Bulakhovskii L.A. Russkii literaturnyi yazyk pervoi poloviny XIX veka. Fonetika. Morfologiya. Udarenie. Sintaksis [Russian literary language of the first half of the $19^{\text {th }}$ century. Phonetics. Morphology. Emphasis. Syntax]. Kiev, 1948. 466 p.

Es'kova N.A. Normy russkogo literaturnogo yazyka XVIII-XIX vekov: Udarenie. Grammaticheskie formy. Varianty slov. Slovar'. Poyasnitel'nye stat'I [Dictionary of 
difficulties of the Russian language of $18^{\text {th }}-19^{\text {th }}$ centuries. Grammatical form]. Moscow, 2008. $578 \mathrm{p}$.

Es'kova N. A. Slovar' trudnostei russkogo yazyka. Grammaticheskie formy [Dictionary of difficulties of the Russian language. Grammatical form]. Moscow, 2014. 535 p.

Kasatkin L. L. (ed.) Russkaya dialektologiya [Russian Dialectology]. $3^{\text {rd }}$ ed. Moscow, 2013. 302 p.

Kalenchuk M.L., Kasatkin L.L., Kasatkina R.F. Bol'shoi orfoepicheskii slovar' russkogo yazyka. [A comprehensive pronouncing dictionary of Russian]. $2^{\text {nd }}$ ed. Moscow, 2017. $1022 \mathrm{p}$.

Kasatkina R.F. [Changes in the prosodic system of the Russian literary language]. Sovremennyi russkii yazyk: Aktivnye protsessy na rubezhe XX-XXI vekov [Modern Russian language: Active processes at the turn of $20^{\text {th }}-21^{\text {th }}$ centuries]. L.P. Krysin (ed.). Moscow, 2008. P. 375-398. (In Russ.)

Russian National Corpus. Available at: http://ruscorpora.ru

Reznichenko I.L. Slovar' udarenii russkogo yazyka [The dictionary of accents of Russian language]. Moscow, 2008. 944 p.

Shtudiner M. A. Slovar' trudnostei russkogo yazyka dlya rabotnikov SMI. Udarenie, proiznoshenie, grammaticheskie formy [Dictionary of Russian language difficulties for media workers. Accent, pronunciation, grammatical forms]. Moscow, 2016. 590 p.

Ushakov D.N. (ed.). Tolkovyi slovar' russkogo yazyka [Explanatory dictionary of Russian language]. In 4 vols. Vol. 1. Moscow, 1935; vol. 2. Moscow, 1938; vol. 3. Moscow, 1939; vol. 4. Moscow, 1940.

Vorontsova V.L. [Active processes in the field of stress]. Russkii yazyk kontsa XX stoletiya (1985-1995) [Russian language of the late twentieth century (1985-1995)]. E. A. Zemskaya (ed.). $2^{\text {nd }}$ ed. Moscow. 2000. P. 305-325. (In Russ.)

Zaliznyak A. A. Ot praslavyanskoi aktsentuatsii k russkoi [From proto-Slavic to Russian accentuation]. Moscow, 1985. 429 p. 